zitten en mede als gevolg van de eigenaardigheid van het lingelsche bankwezen. Ook directeuren van verschillende ondernemingen in dat land schijnen zich tegen dezen vorm te verzetten, hetgeen onlangs nog bleek uit een persdebat over dat onderwerp in de ,Times".

Fien vooraanstaand Fingelsch accountant, een lid der firma Price Waterhouse, heeft enkele juren geleden een lans voor dezen nieuwen balansvorm gehroken, en ofsehoon hij het voor en tegen in zijn geschrift, in verhand met de verschillende gezichtspunten, waaruit dit vraagstuk kan worden bezicn, laat gelden. cn verder als zijn meening uitspreekt, dat de accountants ook den ouden balansvorm kummen onderteekenen, zoo komt hij ten slotte toch tot de conclusie, dat de nieuwe vorm groote voordeelen biedt boven den oude. Wvenwel zal men den onden balansvorm niet kumnen missen, omdat de boeken van het IIoofdkantoor er mede moeten worden afgesloten.

Hoe wordt nu de geconsolideerde balans samengesteld? Alvorens dit te beantwoorden, dient vooraf te gaan de viaag: „Wat wordt geconsolideerd"? cen vraag, welke direct verband houdt met den eisch, welke aan de geconsolideerde balans wordt gesteld. Tndien als eisch wordt gesteld, dat in de eerste platats een inzicht in de liquiditeit van het coneern moet worden verkregen, hetgeen naar mijne meening op den voorgrond behoort te staan, dan staat daarmede strikt genomen vast, dat behalve clatgene, wat de Moedermij in direct behecr hecft, slcehts die onderhonjige ondernemingen in de consolidatic mogen worden hetrokken, walke roor honderd proment door de Moedermij worden bezeten.

Ik bedocl hiermede, dat de Moedermij de Gewone Aandeclen der dochterondernemingen, die dus het eontrôlerecht geven, ten volle in haar bezit moet hebhen. Net een eventuecl preferent kapitaal der dochterondernemingen behoeft dit dus niet het geval te zijn. Fn nu weet ik wel, dat er nog meer dan één anderc doelstelling voor het samenstellen der geconsolidecrde balans mogelijk is, dorh in die gevallen wordt nict voldaan aan den eisch, dat een inzicht in de liquiditeit wordt gegeven, als gevolg waarvan mode geen juist overzicht over do kapitalisatie der onderneming wordt verkregen. En waar dit bestek niet toelaat alle gevallen te hespreken, zal ik dan ook hier op de bijzondere doclstellingen niet nader ingran. Wij berien dus de geconsolidecrde halans nitsluitend in verband met den eisch, dat in de eerste plaats cen inzicht in liquiditeit en kapitalisatic moet worden verkregen. En ofschoon in dit geval, zooals ik recds opmerlitc. uitsluitend de in vollen eigendom bezeten onderneminges mogen worden geconsolideerd, 7.00 zou ik dat toch niet zoo willen opgevat zien, dat h.v. een onderhoorige ondermeming. wollie rolledig door de Conecrn wone Aandeelen bezit, niet in de consolidatie zou worden betrokken. Ook hier geldt het, dat men streng heeft te zijn in het nemen der principiëele beslissing, doch soepel in de uitvocring. Tk wil zelfs nog verder gaan on beweren, dat cen onderhoolige onderneming welke volledig door de Concern Centrale wordt gefinancierd toch in de consolidatie moet worden opgenomen, ook al wordt de $100 \%$ in het gewone aandeclenbezit op verue na niet bereikt.

Bericn wij nu de roornaamste posten, wolke op de geconsolideerde balans voorkomen wat nader, de samenstelling blijkt dan vanzelf.

Nemen wij aan, dat de volgende posten er op voorkomen:

\section{DEBIET :}

Goodwill en Premium

Aandeclen in Onderh. Mijen

Voorschotten aan Onderh.

Mijen

Vaste Activa
Effecten en beleggingen
Voorraden

I) ebiteuren

Vooluitbetaalde kosten

Kas on Kassiers

Het spreckt vanzolf, dat. bij bepalde ondernemingen een andere indeeling der balansposten gewenscht kan zij, doeh als algemeen schema lijkt me bovengenoende opstelling voldoende.

Ik wijs er cvenwel nogmaals op, dat ik bij deze bespreking de kwesties, welke zich voordoen bij de consolidatic van belangen gelegen in landen met schommelende valuta, absolunt buiten beschouwing laat, dalr deze bimen het raam van deze inleiding niet volledig liunnen worden behandeld.

(Wordt vervolgd.)

\section{IETS OVER HET VERBAND TUSSCHEN KOSTPRIJS- BEREKENING EN BOEKHOUDING}

Meer dan eens treft men in de praktijk caleulatics aan, die, in een speciaal boek velzameld, als kostprijsherekeningen aangeduid, den leider der onderneming tot steun dienen voor de door hem vast te stellen verlionpsprijzen der producten zijner onderneming. Deze berekeningen herusten, wat de bij productie van het fabrikaat verbruikte grondstoffen betreft, op een neer of minder nauwkenrige schatting en ten aanzien van de loonkosten op eventucele stukloonprijzen of op een door waarneming bopaald aantal unloonen, vermenigvuldigd met het uurloon. Voor den opslag voor onkosten wordt dan cen dikwerf op traditic berustencl pereentage op de loonkosten aangenomen, welk perecentage in cen gunstig geval wijzjgingen ondergaat op grond van ervaringen in vorige jaren opgedaan. Terhoogd met den winstopslag worden dergelijke ealeulaties dan benut als basis roor len vraagrijg.

Te dikwerf reeds wordt van accountantszijcle op liet finuikend effect van een dergelijke methode gewezen, dat het of mijn weg kan liggen het f'meste dezer handelwijze nogmials in het. licht te stellen. Andors evenwel is het gosteld met de vraag naar het verband tusseben kostprijisealculaties en boekhouding. Vooral voor studecrenclen sehịnt dit v'arastuk dikwijls cen der struikelblokken te vormen bij de toch reeds niet ecnvoudige stof der fabricksadministratic. Mogelijk is het, dat de juist bij dit onderdecl sterk op den voorgrond tredende splitsing in de literatum tussehen de bespreking van de roorlinomende ealculatietypen en de falrreksalministratie zelve, an dit feit niet gcheel onsehuldig is. Daarbij komt dat de taak van opstelling der kostprijsealculaties ook in bedrijven, waarin het verband tussehen deze berekeningen en de boekhouding zeep wel ingezirn wordt, gomeenlijk an cen aparte afdeeling is opgedragen. hetecen mede aanleiding heeft kummen geven tot de misvatting, dat deze kostprijscalculaties cen specifiek op zich zolf stand verschijnscl in de industrizele ondernoming vormen.

Fen en ander schijnt me van genocgzaam helang om op het verband tusschen kostprijsherekening en boekhouding narler de aandacht te vestigen. In het algemeen gezegd, beoogt de bockhouding van een onderneming de veranderingen in het daarin belegd kapitaal in rijn geheel en zijne onderdeelen weer te geven. Al naar gelang van de verschillen, dic zich in deze veranderingen in de verschillende soorten huishoudingen voordoen, krijgt de bockhonding cen versehillend aspect, dat bịj de dubbele methode 0.m. tot nitdrulking liomt in rle grootboekrekeningen. Fen kenmertend versehijnsel in de industriëele ondememingen is nu, dat de wijzigingen in de onderdeclen van het kapitaal binnen de onderneming, door de productie, zooveel grooter zijn dan in de andele ondernemingstypen. Daar het noodig is deze waardewjizigingen in de bockhouding tot uitdrukking te brengen, krijgt deze daardoor een van die van
A andeelenkapitaal (verschillende soorten)

Reserves

Obligatielemingen

Banken

Crediteuren 
andere ondernemingen afwijkend karakter. Dit komt nu in de allereerste plaats tot uitdrukking in de fabricagerekening. die de wijzigingen aangeeft door opoffering van grondstoffen, loonen en fabrikageonkosten, tot product, in het kapitaal veroorzalkt. Waar meerdere productie-processen voorkomen zullen deze weer tot verschillende fabrikage-rekeningen aanleiding geven, terwijl bij andere ondernemingen, war minder een bepaald productic-proces ter fabriceering van onderling gelijksoortige producten, dan wol opoffering van waarden ten bate vau een bepaald fabrikaat, ondersscheiden kan worden, de wijzigingen in het kapitaal in dit product belichaamd in de boekhouding tot uitdrukking gebracht moeten worden. Deze aan de boekhouding to stellen eischen leveren, wat betreft do waardeversehuiving door material- en loonopoffering veroorrakkt, geen bijzondere moeilijkheden. Ander's cvenwel is het gesteld met de z.g. onkosten (onderverdeeling hicrin, laat ili hier buiten beschouwing). Als kenmerk dezer kosten treedt in de cerste plaats naar voren, dat dikwijls nict nauwkeurig valt aan te geven, ten bchoeve van welk productie-proces of product dre gemaakt worden, terwijl bovendien het tijclstip, was'op ze remakt worden en de boekhoudkundige constateering, niet stecds sumenvallen. 'Ter toerekening dezer kosten wordt daarom geb)"uik gemaakt van een zekeren opslag, dic dan bepalald wordt in verband met ervaringen in voorgande periode.

wehter verhinderd een economisch bedrijfsbeheer in somunige gevallen de consequente doolvoering van de noteering der' verandering in het kappitalal door de bookhouding, zoodat soms, warop nader teruggekomen wordt, met cen totaalcal culatie van ook in aard rersehillende fabrikaten genoegen moet worden genomen.

Iit de hierboven geschetste opvattig vloeit dus voort, dat do kostplijiscalculatic, zij het in fabricken met massa- of met stukproductie, cenvoudig behoort tot het terrein der boekhouding. De technick hicrvan verhindert evenwel een te groote combinatic van gegevens in de z.g. hoofdboekcn. Dit is dan de oorzaak, dat de doorgevoerde wcergave der veranderingen in het kapitaal in aparte boeken plaats vindt. dic. dikwerf door bepaalde krachten gevoerd, veelal als kostprijsboekhouding aangeduid worden. Henzolfde soort versehijnsel doct zich trouwens in de meeste ondernemingen voor bij de debitemren- en crediteuren-administratic, warrvan onderdetailleering in bijboeken plaats vindt,

In de industricele onderuemingen bestaan nu verschillen, wat de taak der z.g. kostprijsbockhouding betreft, alsook wat het verband betreft tusschen de hoofdboekhouding en kostprijsboekhouding gelegd.

Wal de talk dor kostprijscaleulatic betreft, wordt gemennlijk onderscheiden tussehen fahrieken met massaproductie en die met stukproductie, warbij die met serieproductic onder de laatste groep gerekend worden. Bij de eerste kan n.l. volstaan worden met een fabrikage-rekening voor de productie van een groep soortgelijke producten, waarbij dan de kostprijs per ecnheid door deeling des totaalkostess op de totale hoeveclheid renheden rerkregen kan worden. Complieatie's kummen zich hicrbij voordoen. doordat productie plaats vindt van groepen artikelen in ard of kwaliteit van elkan verschillend, in welk geval een fabrikage-rekening voor clk dezer grocpen geopend moet worden. Passeert cen product, alvorens tot finale gereedheid te geraken, verschillende afdeelingen, dan kan van clk dezer afdeelingen, beschouwd als zelfstandige producticeenheden, een fabrikage-rekening geopend worden, waardoor dus de kostprijs in icder stadium van productic bekend is. Als typecrend voor elk dezer vor'nen van kostprijsberekening kan gelden, dat de kostprijs steeds bepaald wordt alan het eind van cen bepaalde periode.

Bij de stukproductie kan men onderscheiden in fabrieken, waar gecn en die, waarbij duidelijke afdeelingssplitsing binnen de fabriek optreedt. In het eerste geval is de taak der kostprijsafdeeling den kostprijs van ieder product te calculceren, terwijl in het 2e geval tevens cen calculatie van de afdeelingskosten gewenscht is. Bij deze groep fabrieken komt de kostprijs tot stand bij gereedheid van het product.

Echter zijn er fabrieken, warin het praktisch ondoenlijk is de waardeversehuivingen van grondstoffen, loonen on onkosten tot het product administraicf zuiver te volgen. Dit is het geval in de complexe industriën, warlin cen groot aantal artikelen van onderling verschillenden aard geproduceerd wordt, b.v. hlikwerkfabrieken, ijzelwarenfabrieken, fabrieken van koperen artikelen. slotenfabrieken ete. Kostprịjsberekening per cenheid of serie is praktisch ondoenlijk, terwijl globale kostenberekening tot onjuiste resultaten zou voeren. In dit geval neemt men zijn toevlucht tot extra comptable calculaties de z.g. technische kostprijzen, waarbij, gemcenlijk door den fabricatiechef de kostprijzen naar min of meer nauwketurige waarneming bepaald worden.

Toe nu wordt in elk der bovengenoemde gevallen het verband gclegd tussehen de berekende kostprijzen on de boekhouding? Teelal ziet men in fabrieken met massaproductie, vooral War slechts weinig fabrikagerekeningen noodig zijn. dat do kostprijscalculatic binnen de hoofdboekhouding plaats heeft. In gevallen, warin het antal fabricagerekeningen te groot zou worden om in het gewone grootboek verwerkt te worden, kan één centrale fabrikagerekening in het grootboek geopend worden, en de nadere detaillecring in een sub-groothoek plaats vinken. Een sluitrekcning hierin. Kan dan als contrôle op de juistheid der verwerkte gegevens dienen. Periodick worden de fabrikagerekeningen belast voor de verwerkte grondstoffen, de loonen en de verrekende onkosten. waartegenover de grondstoffenlekening, loonrekening en de rekening verrekende onkosten ontlast worden. De juistheid der fabrikagerekening b] ijkt dan, wat de grondstoffen betreft, nit de overeenstemming tusschen extracomptahle inventarisatic en de vooriaden ef. de giondstoffenrekeningen, wat loonen betreft uit het gladloopen dezer rekening on wat de onkosten aangaat uit de overeenstcmming van de rekening rorrckende onkosten met de werkelijk gemaakte onkosten (het onderhanden werk is hierbij uitgeschakeld).

Formeel anders wordt dit verband gelegd bij de fabrieken met stukproductic. Ilet verst ten deze gaat wel $L$. W. Mawkins in zijin werk "Cost accounts". IIij wenscht n.l. een algeheele scheiding tusschen de "General accounts" en de "Cost accounts", terwijl beide onderdeelen in aparte groothocken volgons de dubbele methode gevocrd worden. Beide groothoeken bicden de mogelijkheid van ecn herekening der fabrikatiewinst, (loordat in de ,General ledger" verantwoord zijn de ingebockte materialen. de betalde loonen en gemaakte onkosten terwijl het materialenverbruik gesteld wordt op het versehil lusschen de debiteering der grondstoffenrekeningen en den eindroorraad volgens inventarisatic, tegenover welk totaal de ophrengst gesteld wordt. terwijl de ,Cost ledger" de verschillende orderekeningen heeft gedebiteerd voor te verrekenen materiaalkosten, loon- en onkosten, waartegenover eveneens de opbrengst gesteld wordt. Overeenstemming in het winstsalde geeft de proef op de juistheid der kostprijsealeulatie, terwịil do oorzaak vall crentuecle verschillen, mogelijk door onjuiste verrekening van materiaalkosten of onkosten door vergelijking der elementen van beide resultatenrekeningen kan blijken. Op snortgclijke wijze wordt in de fabrick van Ludwig Loewe to Berlijn volgens beschrijving van $J$. Litienthal de noteering van ile intelne wanrdeverschuivingen an een apart onderdeel ile $\% . \%$. Betriebsbuchhaltung overgelaten, die, op dezelfde wijze rils bij IImlins, peliodick zich van de juistheid der kostprijscalculatic op de hoogte kan stellen. Daar evenwel de opbreng sten niet, echter wel de voolraadsickeningen en de loomreke- 
ningen in de bedrijfsboekhouding verwerkt worden, is een sluitrekening tusschen het gr'ootboek der hoofdboekhouding en bedrịfsboekhouding noodig. Blijkt dus bij beide schrijvers het verband tussehen kostprijscalculatie en boekhouding dermate nauw, dat afsluiting automatisch de verschillen tusschen verrekend en werkelijk grondstoffenverbruik en onkosten tot uitdrukking brengt, toch behoeft dit verband niet noodwendig uit de boekhouding zelve te blijken. Houdt men n.l. kostprijskaarten voor de diverse gefabriceerde orders, dan kan, door cen envoudige recapitulatie dezer kaarten aan het eind eener periode, de juistheid van de in den kostprijs verrekende kosten geconstateerd worden. Echter is dit tevens de minimum eiseh, dic gesteld mag worden ten opzichte van de controle op de juistheid der kostprijiscalculatie.

Tenslotte nog iets over het verband tussehen kostprijscalculatie en administratie in fabrieken, warin om practische redenen zoomin global- als stukcaleulatic mogelijk is. Hier zal de totaalkostprijs van grocpen, zooveel mogelijk geljjksoortige, of onder soortgelijke omstandigheden geproduceerd, op één fabrikage-rekening verzameld worden. Binnen dit raam worden door den technischen dienst extra-comptable calculaties opgesteld. In dit geval kan dus, indien zoowel verrekende materiaalwaarden als de verrekende onkosten op de fabrikagerekening juist blijken te zijn, ten aanzien van de betrouwbaarheid der technische calculaties geen conclusies getrokken worden. Registrecrt men evenwel de geproducoerde fabrikaten en totaliseert men de onderdeelen, volgens welke de kostprijs berekend is, dan geven deze totalen als bij de stukproductie een inzicht in de sommarische juistheid der verrekende kosten. Weliswaar is hierdoor geen zekerheid verkregen, over de individueele juistheid der berekende kostprijzen, echter geeft een dergelijke methode, gedurende ecuige jaren toegepast, voldoende waarborgen te dezen opzichte.

\section{S. WIJNBERG}

\section{T.O.P.A.}

Tentoonstelling voor Openbare en Particuliere Bedrijfsadministratie. Amsterdam, 19 Juni-19 Juli 1926

De Redactie ontving het onderstaand communiqué:

Wij vernamen, dat de vooruitzichten voor het welslagen dezer Tentoonstelling gunstig zijn, daar de belangstelling zich op zeer voldoende wijze door toezegging van inzendingen voor de verschillende afdeelingen heeft bevestigd. De wandruimte, waarover in de toegewezen 6 zalen van het Stedelijk Museum kan worden beschikt, is reeds geheel voor het aangebodene benoodigd en moet door het plaatsen van schotten worden uitgebreid. Daar waarschijnlijk nog over ecnige binnenlandsche inzendingen overeenstemming zal worden verkregen en bovendien wordt onderhandeld over buitenlandsche zendingen van eenigen omvang, is het niet onmogelijk, dat bij de Directie van het Museum om meer ruimte zal aangeklopt moeten worden.

De Centrale Commissie is over dit verloop zeer tevreden, vooral omdat het tentoonstellingsplan in zoover nieuw is, dat in het bijzonder is gevraagd, datgene te toonen, wat zich onderscheidt door originaliteit van opvatting, toepassing van nieuwe methoden enz., zoodocnde strekkende tot kenmerking van den vooruitgang op administratief gebied. Het is haar een bijzondere voldoening, dat zoowel van de zijde der particuliere ondernemingen als van de overheidsinstellingen, veel medewerking wordt ondervonden.

Gedurende de Tentoonstelling zal een bibliotheek van vak- literatuur met daaraan verbonden leeszalal ter beschikking zijn van de bezockers. De Heer Dr. T. P. Sevensma, Bibliothecaris der Universiteits-bibliotheck van Amsterdan, weld bereid gevonden als Voorzitter der Bibliotheek-commissie op te treden en Mejuffrouw $H$. M. Tetrode, assistente an de HandelsEconomische Bibliotheck, als Secretaresse, met de Heeren Prof. Th. Limperg Jr, II. Keegstre on Ir. F. Donker Duyvis als commissieleden.

Verder zullen in een afzonderlijke zaal van het Museum vergaderingen plaats hebben van vereenigingen, welke zich in eenig contact met de Tentoonstelling willen bevinden. Er is nog gelegenheid hiervoor op cenige data beslag te leggen. In dezelfde zaal zullen lezingen worden gehouden over onderwerpen, welke ter Tentoonstelling zijin gedemonstreerd, in welk geval de lezing zal dienen als inleiding tot een bezoek an de betrokken inzending of inzendingen, of welke verband houden met het Tentoonstellingsprogramma. In den Catalogus zullen hieromtrent alle aanwijzingen te vinden zijn.

Het Algemeen Secretariaat is sedert 1 April gevestigd in het Stedelijk Museum, Kamer 31, to Amsterdam.

EFFICIËNTIE
Red. L. POLAK
$\begin{gathered}\text { (Bijdragen en mededeelingen zende men aan den Secretaris } \\ \text { der Redactie) }\end{gathered}$

\section{BEPERKING VAN WASTE BIJ VERPAKKINGS- MATERIAAL}

Een dezer dagen zagen wij in een bedrijf vall massa-productie een aardige toepassing van een vergelịjking tusschen vóór-en nacaleulatic bij het onderdeel cmballage. IIet was in een fabriek, waar artikelen gemaakt wolden, die stuk voor stuk in een vloeipapiertje gepakt worden, vervolgens worden twee stuks tezamen in cen flink stuk papier gewikkeld en daarna in een carton gedaan en zoo worden zij in kisten, die ieder 100 cartons inhouden, dat is dus 200 stuks, in den handel gebracht

$\mathrm{Bij}$ de vóórcalculatie werden met die verschillende papieren rokening gchouden; het vloeipapier, het inwikkelpapier, en de cartons werden ieder op zich zelf in rekening gebracht. Wekelijks wordt nagegaan of de in de voorealenlatic opgenomen hocveelheden overecnkomen met wat werkelijk verbruikt werd.

Voor ieder soort verpakkingsinateriaal is een kaart ingericht in ecn zichtbaal kaartsystecm (kardex), dat behalve voor deze contrôle tegelịkertijd dienst doet als magazijnkaart voor do voorradige hoeveelheden. Verder is er op aangegeven de maximum- en minimumhoeveelheden, die in voorraad mogen worden gehouden, terwijl met gekleurde ruiters op den rand wordt aangegeven als $\mathrm{cr}^{\prime}$ van een bepaald artikel besteld moet worden, als het bestelde geheel of gedecltelijk werd afgezonden. De kaart geeft daardoor alle inlichtingen, die omtrent de verschillende artikelen gewenscht kunnen worden.

De contrôle om na te gaan in hoeverre de werkelijk verbruikte hoeveelheden van iedere soort verpakkingsmateriaal uverecnstemmen met de hoeveelheden, waarmede in de voorcalculatie werd gerekend, wordt op de volgende wijze verkregen: De magazijnbaas heeft ook de verpakkingsmaterialen onder zijn bcheer. Hij geeft aan den baas van het verpaklingslokaal slechts verpakkingsmaterialen af tegen afgifte van bons. Van die bons maakt de magazijnbaas wekelijks per verpakkingsartikel een afgiftelijst. Op het eind van de week moeten alle nog ongebruikte verpakkingsmaterialen, die in het paklokaal 